The Journal of Animal \& Plant Sciences, 31(3): 2021, Page: 719-732

ISSN (print): 1018-7081: ISSN (online): 2309-8694

\title{
MULTIVARIATE ANALYSIS OF 31 PHENOTYPIC TRAITS AMONG MAJOR PARENTAL LINES OF SUGARCANE BREEDING PROGRAMS IN CHINA
}

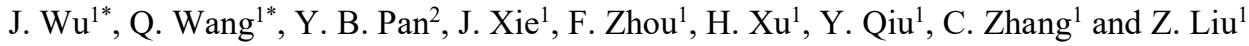 \\ ${ }^{1}$ Ministry of Agriculture of Guangdong Sugarcane Germplasm Resources and Utilization of Scientific Observation Test \\ Station, Institute of Bioengineering, Guangdong Academy of Sciences, Guangzhou 510316, P. R. China \\ ${ }^{2}$ USDA-ARS, Sugarcane Research Unit, Houma, LA70360, USA \\ "Corresponding author’s email: wangqinnan66@163.com; wujiantao2010@163.com
}

\begin{abstract}
Sugarcane parental lines (Saccharum spp. hybrids) serve as a gene pool for sugarcane breeding and genetic improvement. Phenotypic evaluation is the most direct method to study genetic diversity among sugarcane parental lines. Morphological data of 31 phenotypic traits were collected from 130 major sugarcane parental lines for multivariate genetic analysis. The analysis revealed relatively high coefficients of variation and a wide range of frequencies. The extent of genetic diversity among the morphological traits reached a high level with the Shannon-Weiner index $(H s=0.858 \pm 0.026)$. The average genetic diversity index was greater for plant height and stem traits than all other traits. Relatively large genetic distances averaging 0.151 were observed among the 11 series of sugarcane parental lines, with the Guitang-series parental lines exhibiting the most genetic diversity $\left(H_{s}=0.970 \pm 0.078\right)$. A dendrogram based on similarity coefficients clustered 130 major parental lines into three groups and six subgroups. The results provided key information on genetic diversity useful for the screening and selection of potential parents and the design of potential intercrosses.
\end{abstract}

Keywords: sugarcane parental line; phenotype; genetic diversity; diversity index; cluster analysis.

\section{INTRODUCTION}

Sugarcane (Saccharum spp. hybrids) belongs to the Gramineae family, Panicoideae subfamily, Andropogoneae tribe, Saccharinae Benth group of Saccharastrae subtribe, which comprises the "Saccharum Complex" with Erianthus Michx. Sect. Ripidium Henrard, Miscanthus Anderss. Sect. Diandra Keng, Narenga Bor., and Sclerostachya A (Daniels and Roach 1987). The Saccharum genus consists of six species, $S$. officinarum L., S. spontaneum L., S. robustum Brandes and Jeswietex Grassl., S. barberi Jesw., S. sinense Roxb., and S.edule Hassk. These plant genetic resources have provided the foundation for sugarcane variety improvement(Liu et al. 2016).

Modern sugarcane varieties are primarily derived from interspecific hybridizations between the "Noble" cane S. officinarum and related species (Qi et al. 2012). Most sugarcane varieties contain genes from $S$. officinarum, S. spontaneum, and $S$. barberi. Some varieties also have genes from $S$. sinense or $S$. robustum (Deng et al. 2004). However, most sugarcane varieties grown in the world today can be traced back to only a few common progenitors from the progenies of POJ- or Co- series varieties (Deng et al. 2004). This narrow genetic base has hindered the progress of sugarcane improvement. Therefore, it is imperative that sugarcane breeders should investigate the genetic diversity of parental lines and broaden the genetic base by introducing superior genes from wild relatives into sugarcane varieties (Lima et al. 2002; Schenck et al. 2004; Tai and Miller 2001). Genetic diversity analysis is one of the leading methods for studying sugarcane parental lines.

With the development of biotechnology, various DNA-based molecular markers have been used in analyzing the genetic diversity of sugarcane (Qi et al. 2012; Cordeiro et al. 2000; Pan et al. 2004; Pan 2006; Chen et al. 2009; Pan 2010; Liu et al. 2011; You et al. 2016; Liu et al. 2018; Nayak et al. 2014; Wu et al. 2019). However, identification and description of phenotypic traits are still the most direct and basic methods to study sugarcane germplasm resources (Cai and Fan 2006). Compared to molecular markers, phenotypic traits are simple, obvious, easy to collect, economical, effective, and practical. Many researchers have carried out genetic diversity analysis of phenotypic traits in different crops. Liu et al. (2010) evaluated the genetic diversity of 100 sugarcane varieties with 23 phenotypic traits. Zan et al (2014) analyzed the genetic diversity of 104 exotic sugarcane using 29 morphological traits.

The genetic diversity of major parental lines has rarely been studied in China, which could greatly impact their effective utilization. In this study, morphological data on 31 phenotypic traits were analyzed for 130 major 
sugarcane parental lines to analyze genetic diversity, genetic distance, and clustering. The objective of this study was to examine the phenotypic diversity of sugarcane parental lines of sugarcane breeding programs in China for parental selection.

\section{MATERIALS AND METHODS}

Plant materials: We chose 130 parental lines that had been used most frequently in sugarcane hybrid breeding programs in China. The parental lines were originally collected from seven provinces of China mainland, China Taiwan, and the USA. These lines were conserved in the Guangdong sugarcane germplasm resource bank at the Guangdong Provincial Bioengineering Institute (HSBS of the Guangzhou Sugarcane Industry Research Institute) and were classified into 11 series based on geographical origin (Table S1). Among these lines, 10 parental lines were bred in the 1980s, 40 were bred in the 1990s, 50 were bred in the 2000s, and 21 were introduced from China Taiwan, and USA. Twenty-one Yuetang-series parental lines (YT) were from the Guangzhou Sugarcane Industry Research Institute (Guangdong Province, China), 20 Guitang-series parental lines (GT) were from the Sugarcane Research Institute, Guangxi Academy of Agricultural Sciences (Guangxi Province, China), 15 Funong-series parental lines (FN) were from the Sugarcane Research Institute, Fujian Agriculture and Forestry University (Fujian Province, China), 15 Yacheng-series parental lines (YC) were the HSBS of Guangzhou Sugarcane Industry Research Institute (Hainan Province, China), 11 Yunzhe-series parental lines (YZ) were from the Sugarcane Research Institute, Yunnan Academy of Agricultural Sciences (Yunnan Province, China), 8 ROC-series parental lines (ROC) were from the Taiwan Sugar Corporation (Taiwan, China), 10 Neijiang-series parental lines (NJ) were from the Neijiang Academy of Agricultural Sciences (Sichuan Province, China), eight Liucheng-series parental lines (LC) were from the Liucheng Academy of Agricultural Sciences (Guangxi Province, China), five Dezhe-series parental lines (DZ) were from the Dehong Sugarcane Research Institute (Yunnan Province, China), four Gannan-series parental lines (GN) were from the Jiangxi Sugarcane Research Institute (Jiangxi Province, China) (Figure 1). In addition, $13 \mathrm{CP}$-series parental lines (CP) were from the United States Department of AgricultureAgricultural Research Service, Sugarcane Experiment Station, Canal Point, Florida, USA and the Sugarcane Research Unit, Houma, Louisiana, USA

Method of field test and investigation of traits: One hundred and thirty parental lines were maintained in the sugarcane parent nursery of Hainan Sugarcane Breeding Station $\left(18^{\circ} 39^{\prime}\right.$ north latitude and $109^{\circ} 15^{\prime}$ east longitude) during 2016-2017 (one-year Plant-cane and one-year
Ratoon-cane). The plantlets had been germinated in a nursery garden in January 2016, followed by transplantation to the experimental plots in March 2016. Plant-cane was harvested in December 2016 and Ratooncane was planted in 2017. The experimental plots were managed using standard sugarcane parent field techniques.

At the mature stage of Plant-cane and Ratooncane, 10 plants of each parental line were randomly selected for analysis of 31 phenotypic traits according to Cai and Fan (2006) (Table S2). Of the 31 traits, 24 were qualitative, including adventitious root (AR), internode form (IF), internode arrangement (IA), internode color unexposed (ICU), internode color exposed (ICE), growth crack (GC), bloom (Bl), growth bands form (GBF), growth bands color unexposed (GBCU), growth bands color exposed (GBCE), lodging resistance (LR), bud form (BF), bud sulcate (BSu), bud position (BP), bud size (BS), bud wing size (BWS), lateral bud (LB), leaf posture (LP), leaf color (LC), defoliation (De), leaf sheath color (LSC), No. 57 hair group (57HG), auricle (Au) and pulvinus $(\mathrm{Pu})$. The qualitative trait values were recorded during careful observation and comparison. Seven were quantitative traits, including plant height $(\mathrm{PH})$, stem diameter (SD), internode length (IL), Brix (Bx), leaf length (LL), leaf width (LW), and leaf aspect ratio (LAR). The quantitative traits data were presented based on the statistical analysis of two years of data.

Data analysis: Qualitative traits were assigned values according to the survey, while the membership function values were calculated based on the fuzzy membership function. The membership function values of quantitative traits were as follows:

$$
\mu\left(\chi_{i}\right)=\left(\chi_{i}-\chi_{i \min }\right) /\left(\chi_{i \max }-\chi_{i \min }\right) \ldots \ldots \ldots \ldots(i=1,2,3 \ldots 7)
$$

where $\mu\left(\chi_{i}\right)$ represented the membership function value of $i^{\text {th }}$ trait of one clone, $\chi_{i}$ denoted the phenotype value of $i^{\text {th }}$ trait of one clone, $\chi_{i \max }$ or $\chi_{\text {imin }}$ was the maximum or minimum value of $i^{\text {th }}$ trait among all the clones, respectively. According to the formula, each quantitative trait could be defined as a closed interval $[0,1]$. The membership function value of each quantitative trait was classified into 10 grades: $0 \leq 1$ grade $<0.1,0.9 \leq 10$ grade $\leq 1$, each grade interval was 0.1 between 1 and 10 grades (Ai et al. 2017; Lei et al. 2018). The relative frequency of each grade was used for the genetic diversity indices.

Genetic diversity was analyzed from the standard quantification of all phenotypic traits of the sugarcane parental lines. The mean, minimum value, maximum value, standard deviation (SD), variation coefficient (CV), and T-test of seven quantitative traits were calculated using Microsoft Excel 2010 and SPSS 17.0 software. The phenotypic variation number and the Shannon-Weiner diversity $(H s)$ index of each morphological trait were assessed using GenAlEx 6.502 software (Peakall and Smouse 2012; 2006): 


$$
H s=-1 \times \sum \mathrm{p} i \times \operatorname{Ln}\left(\mathrm{p}_{i}\right)
$$

where $\mathrm{p}_{i}$ is the frequency of the $i^{\text {th }}$ grades of one trait. The genetic distance of each series of sugarcane parental lines was calculated by using the following formulae:

$$
D=\frac{-\ln J_{x y}}{\sqrt{J_{x} l_{y}}}, J_{x}=\sum_{i} \sum_{j} X_{i}^{2}, J_{y}=\sum_{i} \sum_{j} Y_{i}^{2}, J_{x}=\sum_{i} \sum_{j} X_{i} Y_{i}
$$

Where $X_{i j}$ is the frequency of the $j^{\text {th }}$ grades of the $i^{\text {th }}$ trait in the $X$ population. Where $Y_{i j}$ is the frequency of the $j^{\text {th }}$ grades of the $i^{\text {th }}$ trait in the $Y$ population. The cluster dendrogram was constructed based on the Sequential Agglomerative Hierarchical Nested clustering (SAHN) and Unweighted Pair Group Mean Average (UPGMA) method with arithmetic averages using NTSYS-pc 2.11e (Rohlf, 2000). The cophenetic correlation analysis was assessed based on a 2-way Mantel method using NTSYS-pc 2.11e (Hegay et al. 2014; Mantel, 1967).

\section{RESULTS}

Variation analysis of 31 morphological traits among sugarcane parental lines: The results showed that the difference of parental lines reached an extremely significant level for the seven quantitative traits (Table S3). The CVs varied from $13.44 \%$ to $19.65 \%$, averaging $15.97 \%$. The internode length (IL), leaf aspect ratio (LAR) and leaf width (LW) are highly variable with CVs $>19.00 \%$. Brix (Bx) and leaf length (LL) have low and relatively stable CVs. The relatively higher $\mathrm{CV}$ values in phenotypic traits indicated that these sugarcane parent lines were highly variable morphologically.

The statistical analysis of the frequencies of different values of the morphological traits reflected a wide range of genetic diversity in sugarcane parents (Table 1). The valuation frequencies of quantitative traits were normally distributed and the frequencies of grades 5 , $3,4,8,5,4$, and 3 of plant height (PH), stem diameter (SD), internode length (IL), Brix (Bx), leaf length (LL), leaf width (LW), and leaf aspect ratio (LAR) were higher, respectively. In stem traits, the grades $1,2,1,2,1,1,2,2$, 1,3 , and 1 of adventitious root (AR), internode form (IF), internode arrangement (IA), internode color unexposed (ICU), internode color exposed (ICE), growth cracks (GC), bloom (Bl), growth bands form (GBF), growth bands color unexposed (GBCU), growth bands (GBCE), and lodging resistance (LR) were in the ascending order, respectively. The grades 2, 1, 2, 1, 3, and 1 of bud form (BF), bud sulcate (BSu), bud position (BP), bud size (BS), bud wing size (BWS), and lateral bud (LB) of bud traits had higher frequencies, respectively, while the grades 3 , $3,1,3,1,1$, and 1 of leaf posture (LP), leaf color (LC), defoliation (De) leaf sheath color (LSC), No.57 hair group $(57 \mathrm{HG})$, auricle $(\mathrm{Au})$, and pulvinus $(\mathrm{Pu})$ were higher, respectively.
Genetic diversity of morphological traits and different serials sugarcane parents: The total number of phenotypic variations of 130 sugarcane parental lines was one hundred and forty-two. Plant height $(\mathrm{PH})$ had the most of phenotypic variation numbers $($ mean $=6.0)$ while lodging resistance (LR) had the least (mean=1.1) (Table 1). The genetic diversity index of each morphological trait was calculated after normalization of the results of the qualitative and quantitative traits (Table 1). The genetic diversity of the morphological traits reached a high level with the Shannon-Weiner index ( $H s=0.858 \pm 0.026)$. Among the 15 stem traits of sugarcane parents, the highest $H s$ value $(1.591 \pm 0.105)$ was associated with $\mathrm{PH}$. $H s$ was $0.907 \pm 0.063$ for total stem traits and $0.748 \pm 0.066$ for total bud traits, respectively. Among the six bud traits, the highest $H_{s}$ value $(1.052 \pm 0.062)$ was recorded for $\mathrm{BF}$. The average $H s$ value of leaf traits was $0.851 \pm 0.079$, and the highest $H s$ value $(1.414 \pm 0.104)$ was associated with the leaf width (LW) trait.

The mean number of phenotypic variations was 3.6, for YT (Table 2). Genetic diversity analysis indicated obvious differences among different series of sugarcane parental lines. Among the 11 series, the highest $H s$ value $(0.970 \pm 0.078)$ was from the GT, followed by $(0.932 \pm 0.088)$ of YC. The lowest $H s$ value $(0.714 \pm 0.090)$ was for LC. The average $I$ and $h$ values of eight series of parental lines, namely, GT, YC, YT, NJ, FN, DZ, CP and $\mathrm{YZ}$, were above the average $H s$ values of all parental lines, while the average $H_{s}$ value of three series of parental lines, namely, ROC, GN and LC, were below the average $H_{s}$ values of all parental lines.

Genetic distance values also varied among the 11 series of sugarcane parental lines, ranging from 0.030 to 0.329 with an average of 0.151 (Table 3). The lowest genetic distance value was 0.030 between CP and GT and the highest genetic distance value of 0.329 was between $\mathrm{DZ}$ and LC. The relatively low genetic distance values among different series may be the result of mutual crossbreeding among various breeding programs.

Genetic diversities of morphological traits were analyzed for 109 parental lines derived from three released eras on mainland China and 21 parental lines introduced from Taiwan, China and the USA (Figure 2). The parental lines derived from the 2000s had the most of Shannon-Weiner index value $(H s=1.039 \pm 0.096)$, followed by those released in the 1990s $(H s=1.009 \pm 0.091)$. The lowest Shannon-Weiner index value was found in parental lines released in the $1980 \mathrm{~s}(H s=0.878 \pm 0.078)$. The Shannon-Weiner index values of $\mathrm{CP}$ and $\mathrm{ROC}$ were intermediate between the 1980 s and 1990s. With the released eras, the genetic diversities of parental lines were increasing. Since the 1980s, a lot of exotic species, e.g. CP and ROC, were continuously imported into China sugarcane breeding program, which partly enriched the genetic diversity level of parent resources of sugarcane of China. 
Table 1. Genetic diversity indices and the frequencies of different valuations in 31 morphological traits of 130 sugarcane parental lines.

\begin{tabular}{|c|c|c|c|c|}
\hline Type & $\begin{array}{c}\text { Phenotypic } \\
\text { trait }\end{array}$ & $\begin{array}{c}\text { Mean number of } \\
\text { phenotypic variation }\end{array}$ & $\begin{array}{c}\text { Shannon-Weiner index } \\
(\text { Mean } \pm \text { SE) }\end{array}$ & $\begin{array}{c}\text { The grade with } \\
\text { higher frequency }\end{array}$ \\
\hline \multirow[t]{16}{*}{ Stem traits } & $\mathrm{PH}$ & 6.0 & $1.591 \pm 0.105$ & $5(20.00 \%)$ \\
\hline & SD & 5.4 & $1.524 \pm 0.096$ & $3(26.15 \%)$ \\
\hline & $\mathrm{AR}$ & 2.7 & $0.841 \pm 0.077$ & $1(47.59 \%)$ \\
\hline & IF & 3.8 & $1.099 \pm 0.046$ & $2(45.28 \%)$ \\
\hline & IA & 2.0 & $0.609 \pm 0.021$ & $1(60.00 \%)$ \\
\hline & $\mathrm{ICU}$ & 2.6 & $0.635 \pm 0.068$ & $2(74.62 \%)$ \\
\hline & ICE & 3.3 & $1.006 \pm 0.083$ & $1(46.15 \%)$ \\
\hline & IL & 5.6 & $1.579 \pm 0.064$ & $4(26.92 \%)$ \\
\hline & WC & 1.5 & $0.207 \pm 0.075$ & $1(91.54 \%)$ \\
\hline & IWP & 3.5 & $1.123 \pm 0.053$ & $2(40.00 \%)$ \\
\hline & GBF & 1.9 & $0.555 \pm 0.061$ & $2(59.23 \%)$ \\
\hline & GBCU & 1.9 & $0.475 \pm 0.065$ & $1(74.62 \%)$ \\
\hline & GBCE & 2.9 & $0.950 \pm 0.045$ & $3(43.85 \%)$ \\
\hline & LR & 1.1 & $0.022 \pm 0.022$ & $1(99.23 \%)$ \\
\hline & $\mathrm{Bx}$ & 4.9 & $1.392 \pm 0.059$ & $8(36.15 \%)$ \\
\hline & Mean & 3.3 & $0.907 \pm 0.063$ & \\
\hline \multirow[t]{7}{*}{ Bud traits } & $\mathrm{BF}$ & 3.4 & $1.052 \pm 0.062$ & $2(40.77 \%)$ \\
\hline & $\mathrm{BD}$ & 2.1 & $0.444 \pm 0.061$ & $1(84.62 \%)$ \\
\hline & $\mathrm{BP}$ & 2.5 & $0.721 \pm 0.087$ & $2(59.23 \%)$ \\
\hline & BS & 2.6 & $0.789 \pm 0.086$ & $1(61.54 \%)$ \\
\hline & BWS & 2.9 & $0.988 \pm 0.035$ & $3(40.00 \%)$ \\
\hline & LB & 2.2 & $0.496 \pm 0.068$ & $1(82.31 \%)$ \\
\hline & Mean & 2.6 & $0.748 \pm 0.066$ & \\
\hline \multicolumn{5}{|l|}{ Leaf traits } \\
\hline & LP & 2.8 & $0.901 \pm 0.073$ & $3(43.08 \%)$ \\
\hline & $\mathrm{LC}$ & 2.5 & $0.667 \pm 0.063$ & $3(70.77 \%)$ \\
\hline & LL & 4.5 & $1.292 \pm 0.101$ & $5(32.31 \%)$ \\
\hline & LW & 4.9 & $1.414 \pm 0.104$ & $4(26.92 \%)$ \\
\hline & LAR & 4.5 & $1.303 \pm 0.098$ & $3(26.92 \%)$ \\
\hline & $\mathrm{De}$ & 2.6 & $0.746 \pm 0.093$ & $1(56.15 \%)$ \\
\hline & LSC & 3.6 & $1.121 \pm 0.055$ & $3(40.00 \%)$ \\
\hline & $57 \mathrm{HG}$ & 2.7 & $0.735 \pm 0.070$ & $1(68.46 \%)$ \\
\hline & $\mathrm{Au}$ & 1.7 & $0.241 \pm 0.068$ & $1(90.77 \%)$ \\
\hline & $\mathrm{Pu}$ & 1.2 & $0.088 \pm 0.060$ & $1(96.92 \%)$ \\
\hline & Mean & 3.1 & $0.851 \pm 0.079$ & \\
\hline Mean & & 4.6 & $0.858 \pm 0.026$ & \\
\hline
\end{tabular}

Table 2. Genetic diversity index values of different series of sugarcane parental lines.

\begin{tabular}{cccc}
\hline Series of parental lines & $\begin{array}{c}\text { Accession } \\
\text { number }\end{array}$ & $\begin{array}{c}\text { Mean number of } \\
\text { phenotypic variation }\end{array}$ & $\begin{array}{c}\text { Shannon-Weiner index } \\
\text { (Mean } \pm \text { SE) }\end{array}$ \\
\hline CP & 13 & 3.1 & $0.860 \pm 0.091$ \\
DZ & 5 & 2.8 & $0.878 \pm 0.074$ \\
FN & 15 & 3.5 & $0.915 \pm 0.097$ \\
GN & 4 & 2.3 & $0.721 \pm 0.063$ \\
GT & 20 & 3.5 & $0.970 \pm 0.078$ \\
LC & 8 & 2.6 & $0.714 \pm 0.090$ \\
NJ & 10 & 3.4 & $0.918 \pm 0.101$ \\
ROC & 8 & 2.7 & $0.750 \pm 0.084$ \\
YC & 15 & 3.4 & $0.932 \pm 0.088$
\end{tabular}




$\begin{array}{cccc}\text { YT } & 21 & 3.6 & 0.924 \pm 0.084 \\ \text { YZ } & 11 & 3.2 & 0.859 \pm 0.096 \\ \text { Mean } & 11.8 & 3.1 & 0.858 \pm 0.026\end{array}$

Table 3. Genetic distance (below diagonal) of 130 sugarcane parental lines.

\begin{tabular}{clllllllllll}
\hline & CP & DZ & FN & GN & GT & LC & NJ & ROC & YC & YT & YZ \\
\hline CP & 0.000 & & & & & & & & & & \\
DZ & 0.145 & 0.000 & & & & & & & & \\
FN & 0.037 & 0.178 & 0.000 & & & & & & & \\
GN & 0.169 & 0.316 & 0.138 & 0.000 & & & & & & \\
GT & $\mathbf{0 . 0 3 0}$ & 0.180 & 0.049 & 0.170 & 0.000 & & & & & \\
LC & 0.120 & $\mathbf{0 . 3 2 9}$ & 0.124 & 0.187 & 0.129 & 0.000 & & & & \\
NJ & 0.117 & 0.267 & 0.101 & 0.252 & 0.108 & 0.234 & 0.000 & & & \\
ROC & 0.058 & 0.216 & 0.057 & 0.169 & 0.062 & 0.122 & 0.147 & 0.000 & & \\
YC & 0.053 & 0.196 & 0.042 & 0.146 & 0.056 & 0.151 & 0.155 & 0.078 & 0.000 & \\
YT & 0.039 & 0.182 & 0.053 & 0.162 & 0.038 & 0.109 & 0.122 & 0.061 & 0.055 & 0.000 & \\
YZ & 0.091 & 0.233 & 0.107 & 0.265 & 0.080 & 0.193 & 0.169 & 0.126 & 0.116 & 0.058 & 0.000 \\
\hline
\end{tabular}

Cluster analysis of sugarcane parental lines based on phenotypic traits: A phylogenetic tree was constructed, on which the 130 sugarcane parental lines were clustered into three distinct groups (I, II, and III) using the similarity coefficient of 0.407 as the threshold, and further division into six distinct subgroups at the similarity coefficient of 0.437 (Figure 3). A 2-way Mantel (Mantel 1967) test was used to test the hypothesis of a precision for phenotypic data to classify the parental lines. The result showed a highly significant correlation of the cophenetic values from the cluster analyses $(r=0.472, P<0.01)$.

Group I comprised of 4 lines, which were further divided into two subgroups (A and B). Subgroup A contained four NJ (NJ03-218, NJ04-70, NJ07-13 and NJ08-5) sharing medium plant height, large stalk, medium internode length, low Brix, short and wide leaf, and low aspect ratio. All lines had more aerial root, drum internode form, no internode wax powder, expansion growth bands form, kelly growth bands, hang down loosely and green leaf (Table S4). Subgroup B consisted of one DZ (DZ03-83) with the features of tall plant height, long internode length, large stalk, low Brix, medium-long and wide leaf, and moderate aspect ratio (Table S4).

Group II comprised of four parental lines that were further divided into only one subgroup $\mathrm{C}$ at the similarity coefficient of 0.437 . Subgroup C contained one CP (CP80-1827), one GT (GT96-154), one YC (YC0661), and one YT (YT89-240), with traits like short plant height, large stalk, long internode length, high Brix, long and narrow leaf, and high aspect ratio (Table S4). All parental lines of subgroup $\mathrm{C}$ had more aerial root, yellow internode color before exposed, no water crack, no bud ditch, low bud position, and no lateral bud (Table S4).

Group III consisted of 121 sugarcane parental lines, which were further clustered into three subgroups
(D, E and F). Subgroup D included ten parental lines with traits such as medium plant height, medium-large stalk, short internode length, medium Brix, short leaf. Most of the parental lines of subgroup D had green internode color before exposed, red internode color after exposed, no expansion growth bands form, grey orange growth bands color after exposed, no bud ditch, reach bud position, middle bud size, no lateral bud, green leaf, degeneration auricle. Subgroup D had one GN, two GT, one NJ, three YC, two YT, and one YZ. Subgroup E contained forty-one accessions, including three $\mathrm{CP}$, three $\mathrm{DZ}$, five $\mathrm{FN}$, one $\mathrm{GN}$, eight $\mathrm{GT}$, four $\mathrm{LC}$, one $\mathrm{NJ}$, four ROC, six YC, four YT, and two YZ, with traits like medium plant height, medium-large stalk, medium internode length, medium Brix, long leaf (Table S4). Most of the parental lines of subgroup E had a zigzag pattern of internode arrangement, thin internode wax powder, grey orange growth bands after exposed, no bud ditch, reach bud position, small bud size, no lateral bud, and green leaf. Subgroup F contained the largest number of 70 parental lines, including nine $\mathrm{CP}$, one $\mathrm{DZ}$, ten $\mathrm{FN}$, two GN, ten GT, three LC, four NJ, four ROC, five YC, $14 \mathrm{YT}$, and eight $\mathrm{YZ}$, with the characteristics of medium plant height, medium-large stalk, medium internode length, medium Brix, and long and wide leaf (Table S4). Most parental lines of subgroup $\mathrm{F}$ had yellow growth bands after exposed, kelly growth bands, no bud ditch, no lateral bud, green leaf, and degeneration auricle.

Thus, there were substantial differences among different groups of parental lines. Only four NJ (NJ03218, NJ04-70, NJ07-13 and NJ08-5) were clustered into one subgroup. Most of the parental lines that belonged to the same series usually clustered into different groups, indicating that there was no correlation between genetic divergence and geographical origin. These results will facilitate the selection of parents for crossing. 


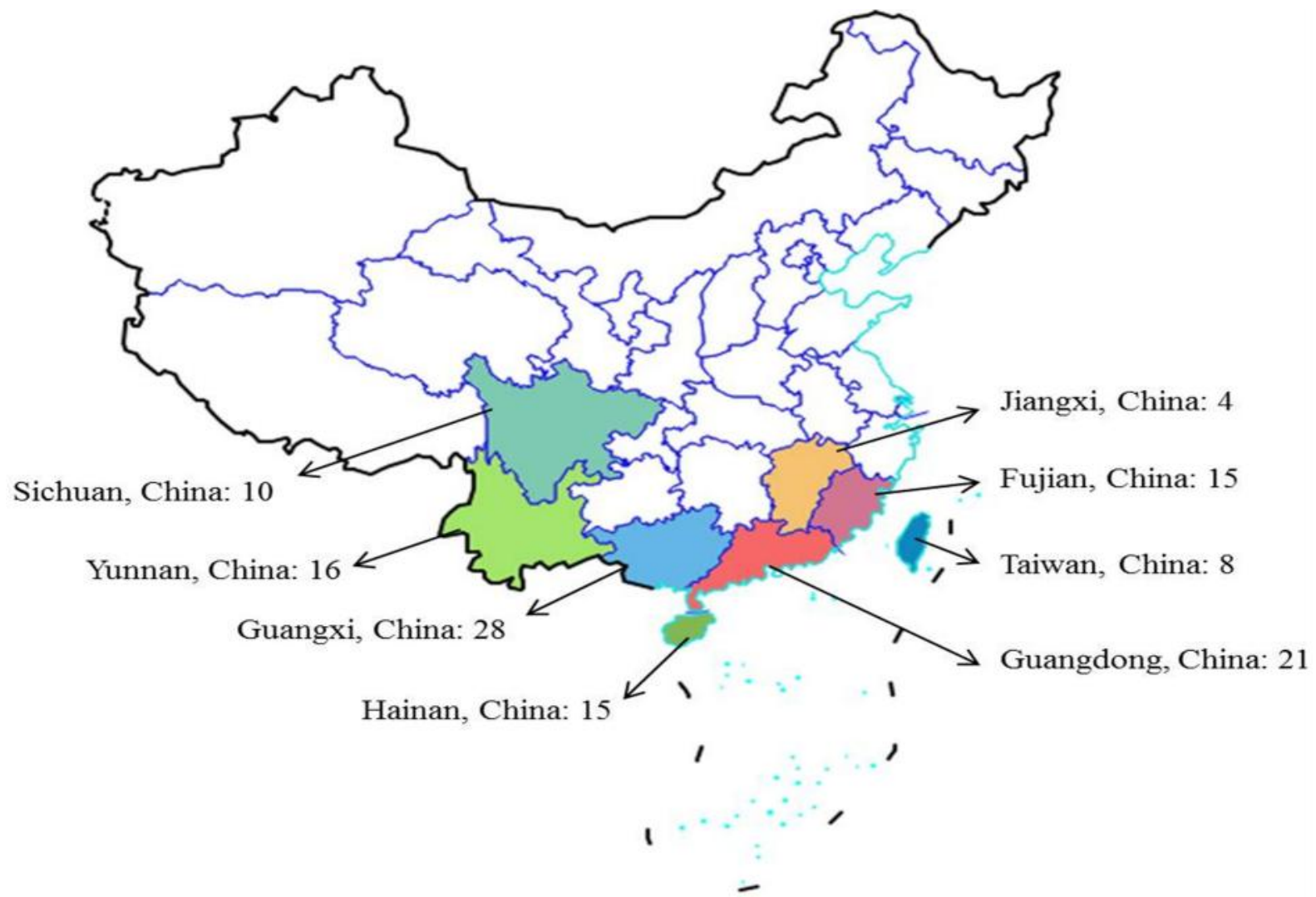

Figure 1: Geographic origin of 117 sugarcane parental lines from eight provinces in China: Guangdong (21 lines), Guangxi (28), Fujian (15), Hainan (15), Yunnan (16), Taiwan (8), Sichuan (10), Jiangxi (4)

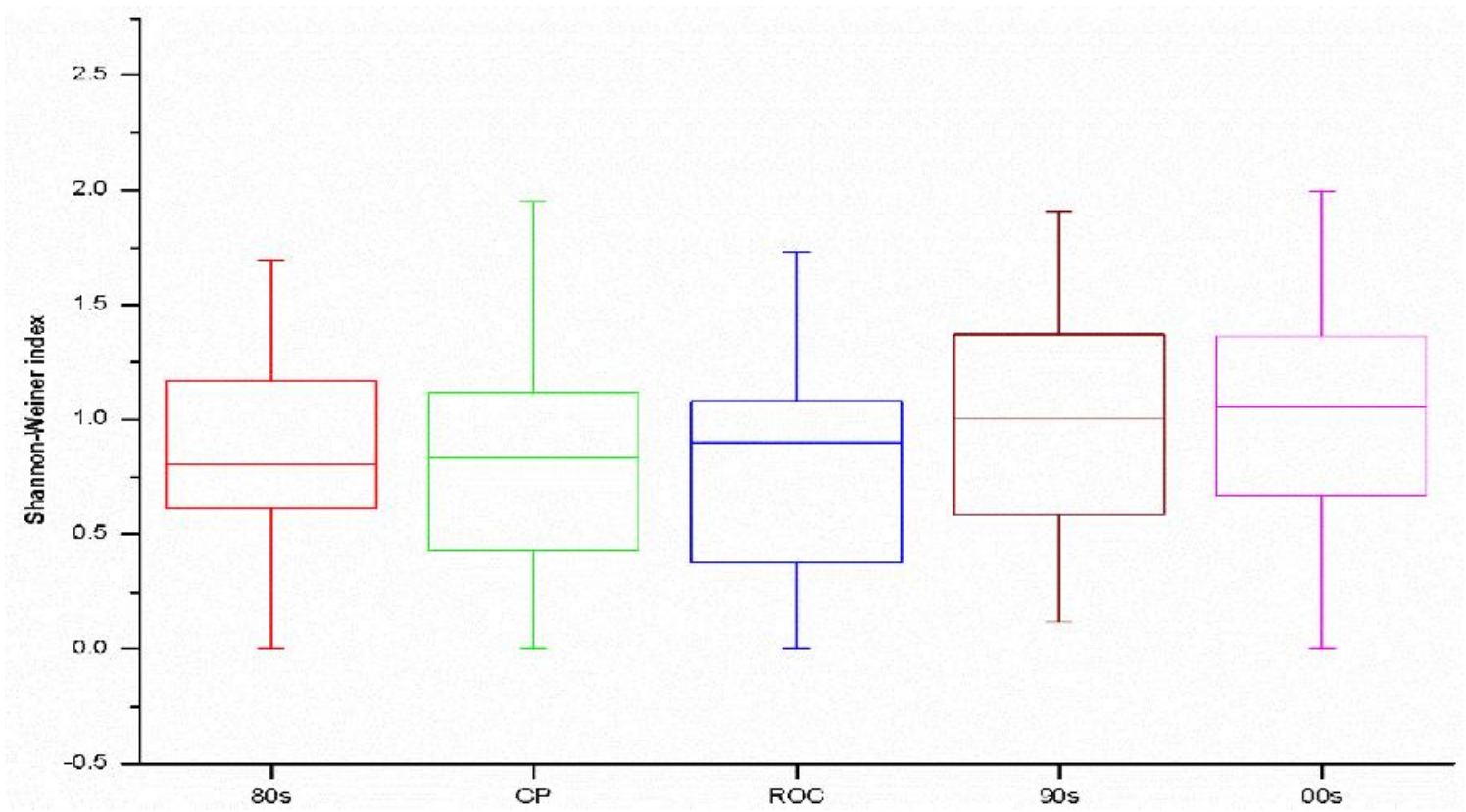

Figure 2: Genetic diversity of morphological traits for parental lines derived from different eras of breeding and introduced location 


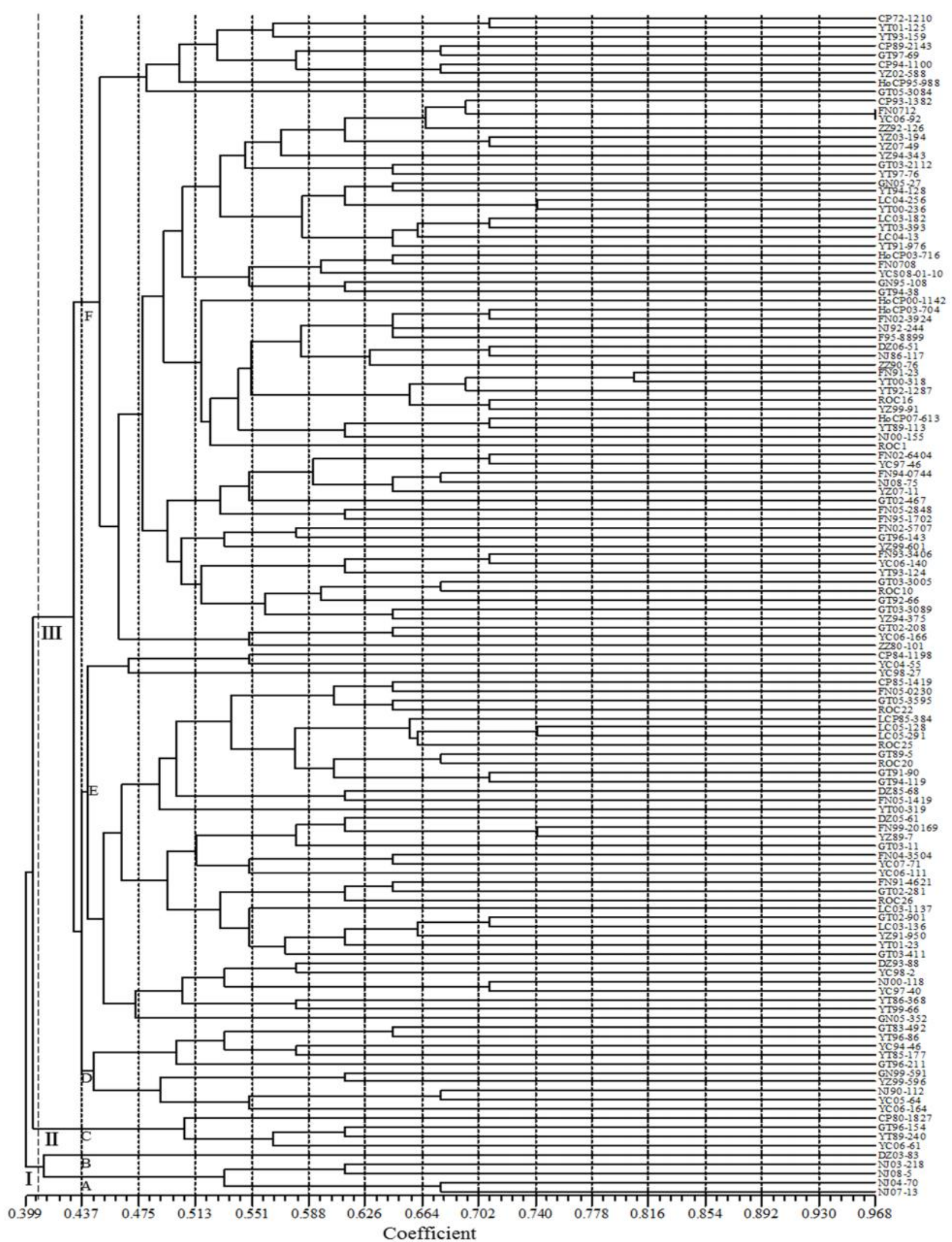

Figure 3: The cluster dendrogram of 130 parental lines was constructed based on the Sequential Agglomerative Hierarchical Nested clustering (SAHN) and unweighted pair group method with arithmetic averages (UPGMA). Three major groups (I, II, and III) and six subgroups (A to F) are shown 


\section{DISCUSSION}

The significance of genetic diversity of sugarcane parental lines: Genetic diversity is a critical part of biodiversity, and the genetic information of the organism is of great theoretical and practical significance. Genetic diversity is a necessary condition for improving yield or resistance to biotic and abiotic stresses (Kefyalew et al. 2000). It is very important to morphologically characterize and classify plant germplasm for genetic improvement, and gene resource preservation and exploitation (Harrison et al. 2000). Nowadays, the data to evaluate the genetic diversity of germplasm resources primarily originate from molecular markers (Bassil et al. 2018; Gitau et al. 2017; Xiong et al. 2016) and phenotypic traits (Lei et al. 2018; Hegay et al. 2014; Kefyalew et al. 2000). Molecular markers are widely used in genetic diversity studies because of their large information content, co-dominance, and environmental stability; however, molecular marker studies are rather difficult to conduct, and expensive. Phenotypic traits are the direct manifestations of biodiversity resulting from long-term natural and artificial selection (Dong et al. 2016), and an intuitive and direct means for studying the genetic diversity of plant germplasm resources. In order to promote the utilization and innovation of sugarcane parent resources, morphology genetic diversity of major parental lines of sugarcane breeding programs in China was conducted using the Shannon-Weiner diversity $(H s)$ index and Nei' genetic distance.

Genetic diversity of major sugarcane parental lines: Sugarcane plants are allopolyploids with highly complex genomes. After long-term hybridization, and artificial and natural selection, a wealth of genetic diversity has accumulated ( $\mathrm{Li}$ et al. 2003). The genetic relatedness/distance among sugarcane parental lines is the foundation for the richness of breeding resources and plays a significant role in parental selection ( $\mathrm{Hu}$ et al. 2012). In the present study, genetic diversity of 130 sugarcane parental lines was evaluated based on 31 highly variable phenotypic traits. These traits showed relatively high $\mathrm{CV}$ values and a wide range of frequency distribution, demonstrating that the 130 sugarcane parental lines can provide excellent genetic resources for breeding of sugarcane varieties. In the previous studies, You et al. (2016) reported that the Shannon's information index $(H s)$ of 14 series ranged from 0.23 to 0.32 while Que et al.(2014) reported the $H s$ of 12 series varied from 0.2411 to 0.5298 which the results were much lower than our present result $(H s=0.858 \pm 0.026)$. Higher genetic diversity values than our results were reported by Liu et al. (2010) on traits such as bud shape $\left(H_{s}=1.1826\right)$, internode color unexposed $\left(H_{s}=1.6865\right)$, internode color exposed $(H s=1.3642)$, bud furrow $(H s=1.0660)$, and hair group $57(H s=1.0299)$. The genetic distance values among the 11 series of sugarcane parental lines ranged from 0.030 to 0.329 with an average of 0.151 , which indicated a high level of genetic diversity. Different from our results, Liu et al. (2018) reported that pairwise genetic identity values among the five groups of sugarcane parental populations ranged from 0.517 to 0.808 . Pairwise genetic similarity coefficients of 0.375 to 0.881 among 107 sugarcane accessions were reported by Que et al. (2014) and of 0.56 to 0.916 among 40 sugarcane accessions by Chen et al. (2009). The difference among the results may be due to the difference in the materials and methodology involved in the studies.

Breeding application of cluster analysis: Geographical factors play an important role in the evolution of plant species (Jaradat and Shahid 2006). Phenotyping-based cluster analysis can roughly reflect the genetic relationship among accessions. However, in our study, the relationship between morphology and geographical origins did not show consistent trends for the 130 sugarcane parental lines. Similar results have been reported in the literature. Based on neighbor-joining cluster analysis, 181 parental lines involved in China's sugarcane breeding programs could be clustered into seven groups (You et al. 2016). Similarly, three groups were reported for 115 sugarcane parental lines (You et al. 2013). Another study showed there were five groups within 96 parental sugarcane cultivars (Qi et al. 2012). In a report by Chen et al. (2009), 35 sugarcane cultivars and five clones of related wild species clustered into five groups. In this study, cluster analysis of 130 sugarcane parental lines based on genetic similarity coefficient values resulted in three groups and six subgroups that comprised of mixed series of parental lines. Among the six subgroups, the F subgroup contained the largest number of parental lines with the YT being the primary materials. Six subgroups had obvious morphological characters, particularly quantitative ones (Table S4). Based on cluster analysis, parental lines with different morphological features can be chosen for intercrossing. For example, most of the parental lines in subgroup C showed high Brix but short plant height, while almost all the parental lines in subgroup B had low Brix but taller plant height. Therefore, parental lines of subgroup $\mathrm{C}$ and $B$ may be intercrossed to develop a segregating population from which new varieties with high sugar and tall plant height may be selected. This strategy may help improve sugar and cane yield through pyramid breeding. The selection of distant relative parents is an effective method to construct generation groups with abundant genetic variation. In this study, the highest genetic distance was between DZ and LC. So in the sugarcane cross-breeding, we should give priority to select parents in DZ and LC for broadening the genetic base. We should configure hybrid combination using the parents with far genetic distance to increase our options. Comprehensive 
cluster analysis to reveal the genetic diversity of sugarcane parental lines is valuable in broadening the genetic base of Chinese sugarcane breeding programs.

Innovation of sugarcane parents in China: In China, more than 200 sugarcane varieties have been released from cross-breeding programs during the last 30 years. However, several issues such as a limited genetic base due to low heterogeneity had impeded the improvement of sugarcane varieties (Chen 2011). Further improvement of sugarcane varieties depends largely on genetic base broadening, parental line selection, and cross combinations. To date, more than 2,000 accessions, including $S$. officinarum, $S$. barberi, $S$. sinense, $S$. spontaneum, $S$. robustum, landrace, chewing cane, advanced hybrids, E. arundinaceus, Miscanthus, Narenga, P. schumach, and P. typhoideum, have been collected in two Sugarcane Germplasm Resource Bank at the HSBS of Guangzhou Sugarcane Industry Research Institute (Hainan Province, China) and the Sugarcane Research Institute of Yunnan Academy of Agricultural Sciences (Yunnan Province, China). The HSBS is the primary sugarcane crossing facility in Mainland China, which undertakes sugarcane crossing, germplasm collection and conservation, and parental line innovation and introduction (Li et al. 2003). Good results have been achieved for the exploitation of $S$. officinarum, $S$. robustum, and $S$. spontaneum, as well as, $E$. arundinaceus (Qi et al. 2012). Some new parents have succeeded in breeding and utilization of such as YC71374, YC05-164, YC07-71, YCS08-01-10, and YC97-46 via introgression breeding with $S$. spontaneum and $E$. arundinaceus, resulting in the release of more than 30 commercial varieties from the YC (Deng et al. 2004). More than $100 \mathrm{YC}$ have been used in sugarcane cross breeding programs in China every year, accounting for more than $30 \%$ of all the crossing parental lines (Qi et al. 2012). The YC have the highest level of genetic diversity based on several molecular marker studies (You et al. 2016; 2013). Due to the germplasm introduction, the genetic diversity of parental lines of sugarcane breeding programs in China was constantly increasing. Some exotic species, e.g. CP72-1210 and ROC22, greatly promoted the development of sugarcane breeding in China. The evaluation of genetic diversity of YC, along with other parental lines such as CP, YT, GT, FN, YZ, ROC, NJ, LC, DZ, and GN from the sugarcane breeding programs in China will be beneficial to the effective utilization of these sugarcane parental lines by increased efficiency of cross hybridizations.

In this study, the phenotypic diversity of sugarcane parental lines based on morphological data was conducted. To know better of genetic relationship of parental lines, the genetic diversity of sugarcane parental lines based on molecular markers should be carried out.
Acknowledgments: This research was funded by the National Natural Science Foundation of China (31701488), the Earmarked Fund for China Agriculture Research System (CARS-170107) and the Science and Technology Project of Guangdong Province (2017A030303049). We thank David M. Burner, Marvellous Zhou, and James Todd for their review comments and language editing.

\section{REFERENCES}

Ai, X., Y. Liang, J. Wang, J. Zheng, Z. Gong, J. Guo, X. $\mathrm{Li}$, and Y. Qu (2017). Genetic diversity and structure of elite cotton germplasm (Gossy pium hirsutum L.) using genome-wide SNP data. Genetica 145(4-5):409-416.

Bassil, N., A. Bidani, K. Hummer, L. J. Rowland, J. Olmstead, P. Lyrene, and C. Richards (2018). Assessing genetic diversity of wild southeastern North American Vaccinium species using microsatellite markers. Genet. Resour. Crop Ev. 65(3):939-950.

Cai, Q., and Y. H. Fan. (2006). Description specification and data standard for sugarcane (Saccharum officinarum L.). China Agriculture Press, Beijing.

Cordeiro, G. M., G. O. Taylor, and R. J. Henry (2000). Characterization of microsatellite markers from sugarcane (Saccharum spp.), a highly polyploid species. Plant Sci. 155(2):161-168.

Chen, P. H., Y. B. Pan, R. K. Chen, L. P. Xu, and Y. Q. Chen (2009). SSR marker-based analysis of genetic relatedness among sugarcane cultivars (Saccharum spp. hybrids) from breeding programs in China and other countries. Sugar Tech 11(4):347-354.

Chen, R. K. (2011). Theory and practice in modern sugarcane breeding. China Agriculture Press, Beijing. 1-19.

Daniels, J., and B. T. Roach (1987). Taxonomy and evolution, pp. 7 - 84, In sugarcane improvement through breeding (D. J. Heinz editor). Elsevier Press, Amsterdam.

Deng, H. H., Q. W. Li, and Z. Y. Chen (2004). Breeding and utilization of new sugarcane parents. Sugarcane 11(3):7-12.

Dong, C. G., J. Wang, X. F. Zhou, X. M. Ma, S. X. Li, Y. $\mathrm{Yu}$, and B. C. Li (2016). Evaluation on genetic diversity of cotton germplasm resources (gossy pium hirsutum L.) on morphological characters. J. Plant Genetic Resources 17(3):438-446.

Gitau, M. M., J. Fan, Y. Xie, and J. Fu (2017). Genetic diversity and association mapping of forage quality in diverse bermudagrass accessions. Euphytica 234:213. 
Hegay, S., M. Geleta, T. Bryngelsson, A. Asanaliev, L. Garkava-Gustavsson, H. Persson Hovmalm, and R. Ortiz (2014). Genetic diversity analysis in Phaseolus vulgaris L. using morphological traits. Genet. Resour. Crop Ev. 61(3):555-566.

Harrison, R. E., J. J. Luby, G. R. Furnier, and J. F. Hancock (2000). Differences in the apportionment of molecular and morphological variation in North American strawberry and the consequences for genetic resource management. Genet. Resour. Crop Ev. 47(6):647-657.

Hu, B. L., Y. Wan, X. Li, J. G. Lei, X. D. Luo, W. G. Yan, and J. K. Xie (2012). Analysis on genetic diversity of phenotypic traits in rice (Oryza sativa) core collection and its comprehensive assessment. Acta Agronomica Sinica 38(5):829-839.

Jaradat, A. A., and M. Shahid (2006). Patterns of phenotypic variation in a germplasm collection of carthamus tinctorius L. from the Middle East. Genet. Resour. Crop Ev. 53(2):225-244.

Kefyalew, T., H. Tefera, K. Assefa, and M. Ayele (2000). Phenotypic diversity for qualitative and phenologic characters in germplasm collections of tef (Eragrostis tef). Genet. Resour. Crop Ev. 47(1):73-80.

Lei, Q. Y., J. J. Zhou, W. H. Zhang, J. Luo, K. N. Wu, and C. L. Long (2018). Morphological diversity of panicle traits in Kam fragrant glutinous rice (Oryza sativa). Genet. Resour. Crop Ev. 65(3):775-786.

Lima, M. L. A., A. A. F. Garcia, K. M. Oliveira, S. Matsuoka, H. Arizono, C. L. de Souza and A. P. de Souza (2002). Analysis of genetic similarity detected by AFLP and coefficient of parentage among genotypes of sugar cane (Saccharum spp.). Theor. Appl. Genet. 104(1):30-38.

Liu, P. W., Y. X. Que, and Y. B. Pan (2011). Highly polymorphic microsatellite DNA markers for sugarcane germplasm evaluation and variety identity testing. Sugar Tech 13(2):129-136.

Liu, X. L., X. J. Li, C. H. Xu, X. Q. Lin, and Z. H. Deng (2016). Genetic diversity of populations of Saccharum spontaneum with different ploidy levels using SSR molecular markers. Sugar Tech 18(4):365-372.

Liu, X. L., L. Ma, Q. Cai, X. M. Ying, X. Lu, H. S. Su, J. Mao, and Y. H. Fan (2010). Genetic diversity analysis of phenotypic traits in Yunnan sugarcane varieties. J. Plant Genetic Resources 11(6):703-708.

Liu, H., X. Yang, Q. You, J. Song, L. Wang, J. Zhang, Z. Deng, R. Ming, and J. Wang (2018). Pedigree, marker recruitment, and genetic diversity of modern sugarcane cultivars in China and the United States. Euphytica 214:48.
Li, Q. W., Z. Y. Chen, and H. Liang (2003). Modern technology for sugarcane improvement. South China University of Technology Press, Guangzhou.

Mantel, N. (1967). The detection of disease clustering and a generalized regression approach. Cancer Res. 27(2):209-220.

Nayak, S. N., J. Song, A. Villa, B. Pathak, T. Ayala-Silva, X. Yang, J. Todd, N. C. Glynn, D. N. Kuhn, B. Glaz, R. A. Gilbert, J. C. Comstock, and J. Wang (2014). Promoting utilization of Saccharum spp. genetic resources through genetic diversity analysis and core collection construction. PLoS One 9(10): e110856.

Pan, Y. B., D. M. Burner, B. L. Legendre, M. P. Grisham, and W. H. White (2004). An assessment of the genetic diversity within a collection of Saccharum spontaneum L. with RAPD-PCR. Genet. Resour. Crop Ev. 51(8):895-903.

Pan, Y. B. (2006). Highly polymorphic microsatellite DNA markers for sugarcane germplasm evaluation and variety identity testing. Sugar Tech 8(4):246-256.

Pan, Y. B. (2010). Databasing molecular identities of sugarcane (Saccharum spp.) clones constructed with microsatellite (SSR) DNA markers. American J. Plant Sciences 1(2):87-94.

Peakall, R., and P. E. Smouse (2012). GenAlEx 6.5: genetic analysis in Excel. Population genetic software for teaching and research--an update. Bioinformatics 28(19):2537-2539.

Peakall, R., and P. E. Smouse (2006). GENALEX 6: genetic analysis in Excel. Population genetic software for teaching and research. Mol. Ecol. Notes 6(1):288-295.

Qi, Y. W., Y. B. Pan, Y. L. Fang, C. M. Zhang, L. N. Fan, H. Y. He, R. Liu, Q. N. Wang, S. M. Liu, F. Y. Liu, Q. W. Li, and H. H. Deng (2012). Genetic structure and diversity of parental cultivars involved in China mainland sugarcane breeding programs as inferred from DNA microsatellites. J. Integr. Agr. 11(11):1794-1803.

Que, Y. X., Y. B. Pan, Y. H. Lu, C. Yang, Y. T. Yang, N. Huang, and L. P. Xu. (2014). Genetic analysis of diversity within a Chinese local sugarcane germplasm based on start codon targeted polymorphism. Biomed Res. Int. 2014:468375.

Rohlf, F. J. (2000). NTSYS pc2.1: Numerical taxonomy and multivariate analysis system version 2.1 . Applied Biostatistics Inc., New York.

Schenck, S., M. W. Crepeau, K. K. Wu, P. H. Moore, Q. Yu, and R. Ming (2004). Genetic diversity and relationships in native Hawaiian Saccharum officinarum sugarcane. J. Hered. 95(4):327-331.

Tai, P. Y. P., and J. D. Miller (2001). A core collection for Saccharum officinarum L. from the world 
collection of sugarcane. Crop Sci. 41(3):879885.

Wu J.T., Q.N. Wang, J. Xie, Y. Pan, F. Zhou, Y.Q. Guo, H.L. Chang, H.Y. Xu, W. Zhang, C.M. Zhang, and Y.S. Qiu (2019). SSR marker-assisted management of parental germplasm in sugarcane (Saccharum spp. hybrids) breeding programs. Agronomy 9: 449.

Xiong, H. Z., A. N. Shi, B. Q. Mou, J. Qin, D. Motes, W. G. Lu, J. B. Ma, Y. J. Weng, W. Yang, and D. $\mathrm{X}$. Wu (2016). Genetic diversity and population structure of cowpea (Vigna unguiculata L. Walp). PLoS One 11(8): e160941.

You, Q., Y. B. Pan, L. P. Xu, S. W. Gao, Q. N. Wang, Y. C. Su, Y. Q. Yang, Q. B. Wu, D. G. Zhou, and
Y. X. Que (2016). Genetic diversity analysis of sugarcane germplasm based on fluorescencelabeled simple sequence repeat markers and a capillary electrophoresis-based genotyping platform. Sugar Tech 18(4):380-390.

You, Q., L. P. Xu, Y. F. Zheng, and Y. X. Que. (2013). Genetic diversity analysis of sugarcane parents in Chinese breeding programmes using gSSR markers. The Scientific World J. 613062.

Zan, F. G., C. W. Wu, P. F. Zhao, J. Zhao, H. M. Xia, K. Yang, Y. Li, W. Qin, and J. Y. Liu (2014). Study on phenotypic diversity in exotic sugarcane germplasm. Southwest China J. Agricultural Sciences 27(4):1369-1373.

TableS1: The amount, series, and origin of sugarcane parents

\begin{tabular}{|c|c|c|c|c|}
\hline NO. & Clone name & Bred era & Series & Origin \\
\hline 1 & CP72-1210 & Introduced & $\mathrm{CP}$ & USA \\
\hline 2 & CP80-1827 & Introduced & $\mathrm{CP}$ & USA \\
\hline 3 & CP84-1198 & Introduced & $\mathrm{CP}$ & USA \\
\hline 4 & CP85-1419 & Introduced & $\mathrm{CP}$ & USA \\
\hline 5 & CP89-2143 & Introduced & $\mathrm{CP}$ & USA \\
\hline 6 & CP93-1382 & Introduced & $\mathrm{CP}$ & USA \\
\hline 7 & CP94-1100 & Introduced & $\mathrm{CP}$ & USA \\
\hline 8 & HoCР00-1142 & Introduced & $\mathrm{CP}$ & USA \\
\hline 9 & НоСР03-704 & Introduced & $\mathrm{CP}$ & USA \\
\hline 10 & HoCP03-716 & Introduced & $\mathrm{CP}$ & USA \\
\hline 11 & НоСР07-613 & Introduced & $\mathrm{CP}$ & USA \\
\hline 12 & НоСР95-988 & Introduced & $\mathrm{CP}$ & USA \\
\hline 13 & LCP85-384 & Introduced & $\mathrm{CP}$ & USA \\
\hline 14 & DZ03-83 & $00 \mathrm{~s}$ & $\mathrm{DZ}$ & Yunnan, China \\
\hline 15 & DZ05-61 & $00 \mathrm{~s}$ & $\mathrm{DZ}$ & Yunnan, China \\
\hline 16 & DZ06-51 & $00 \mathrm{~s}$ & $\mathrm{DZ}$ & Yunnan, China \\
\hline 17 & DZ85-68 & $80 \mathrm{~s}$ & $\mathrm{DZ}$ & Yunnan, China \\
\hline 18 & DZ93-88 & $90 \mathrm{~s}$ & $\mathrm{DZ}$ & Yunnan, China \\
\hline 19 & FN02-3924 & $00 \mathrm{~s}$ & $\mathrm{FN}$ & Fujian, China \\
\hline 20 & FN02-5707 & $00 \mathrm{~s}$ & $\mathrm{FN}$ & Fujian, China \\
\hline 21 & FN02-6404 & $00 \mathrm{~s}$ & $\mathrm{FN}$ & Fujian, China \\
\hline 22 & FN04-3504 & $00 \mathrm{~s}$ & $\mathrm{FN}$ & Fujian, China \\
\hline 23 & FN05-0230 & $00 \mathrm{~s}$ & $\mathrm{FN}$ & Fujian, China \\
\hline 24 & FN05-1419 & $00 \mathrm{~s}$ & $\mathrm{FN}$ & Fujian, China \\
\hline 25 & FN05-2848 & $00 \mathrm{~s}$ & $\mathrm{FN}$ & Fujian, China \\
\hline 26 & FN0708 & $00 \mathrm{~s}$ & $\mathrm{FN}$ & Fujian, China \\
\hline 27 & FN0712 & $00 \mathrm{~s}$ & $\mathrm{FN}$ & Fujian, China \\
\hline 28 & FN91-23 & $90 \mathrm{~s}$ & $\mathrm{FN}$ & Fujian, China \\
\hline 29 & FN91-4621 & $90 \mathrm{~s}$ & $\mathrm{FN}$ & Fujian, China \\
\hline 30 & FN93-3406 & $90 \mathrm{~s}$ & $\mathrm{FN}$ & Fujian, China \\
\hline 31 & FN94-0744 & $90 \mathrm{~s}$ & $\mathrm{FN}$ & Fujian, China \\
\hline 32 & FN95-1702 & $90 \mathrm{~s}$ & $\mathrm{FN}$ & Fujian, China \\
\hline 33 & FN99-20169 & $90 \mathrm{~s}$ & $\mathrm{FN}$ & Fujian, China \\
\hline 34 & GN05-27 & $00 \mathrm{~s}$ & GN & Jiangxi, China \\
\hline 35 & GN05-352 & $00 \mathrm{~s}$ & GN & Jiangxi, China \\
\hline 36 & GN95-108 & $90 \mathrm{~s}$ & GN & Jiangxi, China \\
\hline 37 & GN99-591 & $90 \mathrm{~s}$ & GN & Jiangxi, China \\
\hline 38 & GT02-208 & 00s & GT & Guangxi, China \\
\hline 39 & GT02-281 & $00 \mathrm{~s}$ & $\mathrm{GT}$ & Guangxi, China \\
\hline 40 & GT02-467 & 00s & GT & Guangxi, China \\
\hline 41 & GT02-901 & $00 \mathrm{~s}$ & $\mathrm{GT}$ & Guangxi, China \\
\hline
\end{tabular}




\begin{tabular}{|c|c|c|c|c|}
\hline 42 & GT03-11 & $00 \mathrm{~s}$ & GT & Guangxi, China \\
\hline 43 & GT03-2112 & $00 \mathrm{~s}$ & GT & Guangxi, China \\
\hline 44 & GT03-3005 & $00 \mathrm{~s}$ & GT & Guangxi, China \\
\hline 45 & GT03-3089 & $00 \mathrm{~s}$ & GT & Guangxi, China \\
\hline 46 & GT03-411 & $00 \mathrm{~s}$ & GT & Guangxi, China \\
\hline 47 & GT05-3084 & $00 \mathrm{~s}$ & GT & Guangxi, China \\
\hline 48 & GT05-3595 & $00 \mathrm{~s}$ & GT & Guangxi, China \\
\hline 49 & GT83-492 & $80 \mathrm{~s}$ & GT & Guangxi, China \\
\hline 50 & GT89-5 & $80 \mathrm{~s}$ & GT & Guangxi, China \\
\hline 51 & GT91-90 & $90 \mathrm{~s}$ & GT & Guangxi, China \\
\hline 52 & GT92-66 & $90 \mathrm{~s}$ & GT & Guangxi, China \\
\hline 53 & GT94-119 & $90 \mathrm{~s}$ & GT & Guangxi, China \\
\hline 54 & GT94-38 & $90 \mathrm{~s}$ & GT & Guangxi, China \\
\hline 55 & GT96-143 & $90 \mathrm{~s}$ & GT & Guangxi, China \\
\hline 56 & GT96-154 & $90 \mathrm{~s}$ & GT & Guangxi, China \\
\hline 57 & GT96-211 & $90 \mathrm{~s}$ & GT & Guangxi, China \\
\hline 58 & GT97-69 & $90 \mathrm{~s}$ & GT & Guangxi, China \\
\hline 59 & LC03-1137 & $00 \mathrm{~s}$ & $\mathrm{LC}$ & Guangxi, China \\
\hline 60 & LC03-136 & $00 \mathrm{~s}$ & $\mathrm{LC}$ & Guangxi, China \\
\hline 61 & LC03-182 & $00 \mathrm{~s}$ & LC & Guangxi, China \\
\hline 62 & LC04-13 & $00 \mathrm{~s}$ & $\mathrm{LC}$ & Guangxi, China \\
\hline 63 & LC04-256 & $00 \mathrm{~s}$ & LC & Guangxi, China \\
\hline 64 & LC05-128 & $00 \mathrm{~s}$ & LC & Guangxi, China \\
\hline 65 & LC05-291 & $00 \mathrm{~s}$ & $\mathrm{LC}$ & Guangxi, China \\
\hline 66 & NJ00-118 & $00 \mathrm{~s}$ & NJ & Sichuan, China \\
\hline 67 & NJ00-155 & $00 \mathrm{~s}$ & NJ & Sichuan, China \\
\hline 68 & NJ03-218 & $00 \mathrm{~s}$ & NJ & Sichuan, China \\
\hline 69 & NJ04-70 & $00 \mathrm{~s}$ & NJ & Sichuan, China \\
\hline 70 & NJ07-13 & $00 \mathrm{~s}$ & NJ & Sichuan, China \\
\hline 71 & NJ08-5 & $00 \mathrm{~s}$ & NJ & Sichuan, China \\
\hline 72 & NJ08-75 & $00 \mathrm{~s}$ & NJ & Sichuan, China \\
\hline 73 & NJ86-117 & $80 \mathrm{~s}$ & NJ & Sichuan, China \\
\hline 74 & NJ90-112 & $90 \mathrm{~s}$ & NJ & Sichuan, China \\
\hline 75 & NJ92-244 & $90 \mathrm{~s}$ & NJ & Sichuan, China \\
\hline 76 & F95-8899 & Introduced & ROC & Taiwan, China \\
\hline 77 & ROC1 & Introduced & ROC & Taiwan, China \\
\hline 78 & ROC10 & Introduced & ROC & Taiwan, China \\
\hline 79 & ROC16 & Introduced & ROC & Taiwan, China \\
\hline 80 & ROC20 & Introduced & $\mathrm{ROC}$ & Taiwan, China \\
\hline 81 & ROC22 & Introduced & ROC & Taiwan, China \\
\hline 82 & ROC25 & Introduced & ROC & Taiwan, China \\
\hline 83 & ROC26 & Introduced & ROC & Taiwan, China \\
\hline 84 & YC04-55 & $00 \mathrm{~s}$ & $\mathrm{YC}$ & Hainan, China \\
\hline 85 & YC05-64 & $00 \mathrm{~s}$ & $\mathrm{YC}$ & Hainan, China \\
\hline 86 & YC06-111 & $00 \mathrm{~s}$ & YC & Hainan, China \\
\hline 87 & YC06-140 & $00 \mathrm{~s}$ & $\mathrm{YC}$ & Hainan, China \\
\hline 88 & YC06-164 & $00 \mathrm{~s}$ & $\mathrm{YC}$ & Hainan, China \\
\hline 89 & YC06-166 & $00 \mathrm{~s}$ & $\mathrm{YC}$ & Hainan, China \\
\hline 90 & YC06-61 & $00 \mathrm{~s}$ & $\mathrm{YC}$ & Hainan, China \\
\hline 91 & YC06-92 & $00 \mathrm{~s}$ & $\mathrm{YC}$ & Hainan, China \\
\hline 92 & YC07-71 & $00 \mathrm{~s}$ & $\mathrm{YC}$ & Hainan, China \\
\hline 93 & YC94-46 & $90 \mathrm{~s}$ & $\mathrm{YC}$ & Hainan, China \\
\hline 94 & YC97-40 & $90 \mathrm{~s}$ & $\mathrm{YC}$ & Hainan, China \\
\hline 95 & YC97-46 & $90 \mathrm{~s}$ & $\mathrm{YC}$ & Hainan, China \\
\hline 96 & YC98-2 & $90 \mathrm{~s}$ & YC & Hainan, China \\
\hline 97 & YC98-27 & $90 \mathrm{~s}$ & $\mathrm{YC}$ & Hainan, China \\
\hline 98 & YCS08-01-10 & $00 \mathrm{~s}$ & $\mathrm{YC}$ & Hainan, China \\
\hline 99 & YT00-236 & $00 \mathrm{~s}$ & YT & Guangdong, China \\
\hline 100 & YT00-318 & $00 \mathrm{~s}$ & YT & Guangdong, China \\
\hline 101 & YT00-319 & $00 \mathrm{~s}$ & YT & Guangdong, China \\
\hline 102 & YT01-125 & $00 \mathrm{~s}$ & YT & Guangdong, China \\
\hline 103 & YT01-23 & $00 \mathrm{~s}$ & YT & Guangdong, China \\
\hline
\end{tabular}




\begin{tabular}{|c|c|c|c|c|}
\hline 104 & YT03-393 & $00 \mathrm{~s}$ & $\mathrm{YT}$ & Guangdong, China \\
\hline 105 & YT85-177 & $80 \mathrm{~s}$ & YT & Guangdong, China \\
\hline 106 & YT86-368 & $80 \mathrm{~s}$ & YT & Guangdong, China \\
\hline 107 & YT89-113 & $80 \mathrm{~s}$ & $\mathrm{YT}$ & Guangdong, China \\
\hline 108 & YT89-240 & $80 \mathrm{~s}$ & YT & Guangdong, China \\
\hline 109 & YT91-976 & $90 \mathrm{~s}$ & YT & Guangdong, China \\
\hline 110 & YT92-1287 & $90 \mathrm{~s}$ & YT & Guangdong, China \\
\hline 111 & YT93-124 & $90 \mathrm{~s}$ & YT & Guangdong, China \\
\hline 112 & YT93-159 & $90 \mathrm{~s}$ & YT & Guangdong, China \\
\hline 113 & YT94-128 & $90 \mathrm{~s}$ & YT & Guangdong, China \\
\hline 114 & YT96-86 & $90 \mathrm{~s}$ & $\mathrm{YT}$ & Guangdong, China \\
\hline 115 & YT97-76 & $90 \mathrm{~s}$ & YT & Guangdong, China \\
\hline 116 & YT99-66 & $90 \mathrm{~s}$ & $\mathrm{YT}$ & Guangdong, China \\
\hline 117 & ZZ80-101 & $80 \mathrm{~s}$ & YT & Guangdong, China \\
\hline 118 & ZZ90-76 & $90 \mathrm{~s}$ & YT & Guangdong, China \\
\hline 119 & ZZ92-126 & $90 \mathrm{~s}$ & $\mathrm{YT}$ & Guangdong, China \\
\hline 120 & YZ02-588 & $00 \mathrm{~s}$ & $\mathrm{YZ}$ & Yunnan, China \\
\hline 121 & YZ03-194 & $00 \mathrm{~s}$ & $\mathrm{YZ}$ & Yunnan, China \\
\hline 122 & YZ07-11 & $00 \mathrm{~s}$ & $\mathrm{YZ}$ & Yunnan, China \\
\hline 123 & YZ07-49 & $00 \mathrm{~s}$ & $\mathrm{YZ}$ & Yunnan, China \\
\hline 124 & YZ89-7 & $80 \mathrm{~s}$ & $\mathrm{YZ}$ & Yunnan, China \\
\hline 125 & YZ91-950 & $90 \mathrm{~s}$ & $\mathrm{YZ}$ & Yunnan, China \\
\hline 126 & YZ94-343 & $90 \mathrm{~s}$ & $\mathrm{YZ}$ & Yunnan, China \\
\hline 127 & YZ94-375 & $90 \mathrm{~s}$ & $\mathrm{YZ}$ & Yunnan, China \\
\hline 128 & YZ99-596 & $90 \mathrm{~s}$ & $\mathrm{YZ}$ & Yunnan, China \\
\hline 129 & YZ99-601 & $90 \mathrm{~s}$ & $\mathrm{YZ}$ & Yunnan, China \\
\hline 130 & YZ99-91 & $90 \mathrm{~s}$ & $\mathrm{YZ}$ & Yunnan, China \\
\hline
\end{tabular}

Table S2: Descriptor and valuation of morphological traits evaluated in 130 sugarcane parental lines.

\begin{tabular}{|c|c|c|c|c|}
\hline Type & Trait & $\begin{array}{l}\text { Trait } \\
\text { code }\end{array}$ & Descriptor & Valuation \\
\hline \multirow{15}{*}{$\begin{array}{l}\text { Stem } \\
\text { traits }\end{array}$} & Plant height & $\mathrm{PH}$ & The height of stem in mature stage & Measured by using ruler \\
\hline & Stem diameter & SD & The diameter of stem in mature stage & Measured by using caliper \\
\hline & Adventitious root & AR & The roots on aerial stems & None $=1$, less $=2$, more $=3$ \\
\hline & Internode form & IF & $\begin{array}{l}\text { The form of stem between leaf scar and } \\
\text { growth bands }\end{array}$ & $\begin{array}{l}\text { Cone }=1 \text {, cylinder }=2 \text {, drum }=3 \text {, slender } \\
\text { waist }=4 \text {, curved }=5 \text {, inverted taper }=6\end{array}$ \\
\hline & $\begin{array}{l}\text { Internode } \\
\text { arrangement }\end{array}$ & IA & $\begin{array}{l}\text { The overall shape of stem in mature } \\
\text { stage }\end{array}$ & Zigzag pattern $=1$, upright pattern $=2$ \\
\hline & $\begin{array}{l}\text { Internode color } \\
\text { unexposed }\end{array}$ & ICU & $\begin{array}{l}\text { The color of stem between leaf scar } \\
\text { and growth bands unexposed }\end{array}$ & Yellow $=1$, green $=2$, red $=3$, purple $=4$ \\
\hline & $\begin{array}{l}\text { Internode color } \\
\text { exposed }\end{array}$ & ICE & $\begin{array}{l}\text { The color of stem between leaf scar } \\
\text { and growth bands exposed }\end{array}$ & Yellow $=1$, green $=2$, red $=3$, purple $=4$ \\
\hline & Internode length & IL & $\begin{array}{l}\text { The length of stem between leaf scar } \\
\text { and growth bands }\end{array}$ & Measured by using ruler \\
\hline & Growth cracks & GC & $\begin{array}{l}\text { The crack in stem between leaf scar } \\
\text { and growth bands }\end{array}$ & None $=1$, have $=2$ \\
\hline & Bloom: & $\mathrm{Bl}$ & $\begin{array}{l}\text { A white, powder like coating } \\
\text { sometimes found on stem surface }\end{array}$ & None $=1$, thin $=2$, middle $=3$, thick $=4$ \\
\hline & $\begin{array}{l}\text { Growth bands } \\
\text { form }\end{array}$ & GBF & $\begin{array}{l}\text { The form of growth bands which above } \\
\text { root zone }\end{array}$ & Non-expansion $=1$, expansion $=2$ \\
\hline & $\begin{array}{l}\text { Growth bands } \\
\text { color unexposed }\end{array}$ & GBCU & The color of growth bands unexposed & Yellow green $=1$, green $=2$ \\
\hline & $\begin{array}{l}\text { Growth bands } \\
\text { color exposed }\end{array}$ & GBCE & The color of growth bands exposed & Yellow green $=1$, green $=2$, grey orange $=3$ \\
\hline & Lodging resistance & LR & Whether to fall when the wind blows & Low resistance $=1$, highly resistance $=2$ \\
\hline & Brix & $\mathrm{Bx}$ & $\begin{array}{l}\text { The average of the sugarcane-juice brix } \\
\text { in mature stage }\end{array}$ & $\begin{array}{l}\text { Measured by using Hand held } \\
\text { refractometer }\end{array}$ \\
\hline \multirow[t]{2}{*}{$\begin{array}{l}\text { Bud } \\
\text { traits }\end{array}$} & Bud form & $\mathrm{BF}$ & The form of lateral bud & $\begin{array}{l}\text { Roundness }=1 \text {, oval }=2 \text {, triangle }=3 \text {, } \\
\text { obovate }=4 \text {, rhombus }=5 \text {, elliptic }=6 \text {, } \\
\text { rectangle }=7\end{array}$ \\
\hline & Bud sulcate: & $\mathrm{BSu}$ & The groove of lateral bud above bud & None $=1$, shallow $=2$, deep $=3$ \\
\hline
\end{tabular}




\begin{tabular}{|c|c|c|c|c|}
\hline \multirow{14}{*}{$\begin{array}{l}\text { Leaf } \\
\text { traits }\end{array}$} & Bud position & $\mathrm{BP}$ & The position of lateral buds on stem & Low $=1$, reach $=2$, high $=3$ \\
\hline & Bud size & BS & Bud size & Small $=1$, middle $=2$, big $=3$ \\
\hline & Bud wing size & BWS & \multirow{2}{*}{$\begin{array}{l}\text { Bud wing size } \\
\text { Growth situation of lateral bud in } \\
\text { mature stage }\end{array}$} & None $=1$, narrow $=2$, wide $=3$ \\
\hline & Adventitious bud & $\mathrm{AB}$ & & None $=1$, less $=2$, more $=3$ \\
\hline & Leaf posture & LP & The posture of leaf in mature stage & Erect $=1$, reptent $=2$, spreading $=3$ \\
\hline & Leaf color & $\mathrm{LC}$ & The color of leaf in mature stage & Yellow green $=1$, light green $=2$, green $=3$ \\
\hline & Leaf length & LL & The length of +3 leaf in mature stage & Measured by using ruler \\
\hline & Leaf width & LW & The width of +3 leaf in mature stage & Measured by using ruler \\
\hline & Leaf aspect ratio & LAR & $\begin{array}{l}\text { The aspect ratio of length and width of } \\
\text { leaf }\end{array}$ & LL/LW \\
\hline & Defoliation & De & $\begin{array}{l}\text { The degree of leaf sheath enclosing the } \\
\text { stem in mature stage }\end{array}$ & Hard $=1$, medium $=2$, hard $=3$ \\
\hline & $\begin{array}{l}\text { Leaf sheath } \\
\text { color }\end{array}$ & LSC & The color of leaf sheath in mature stage & $\begin{array}{l}\text { Yellow green }=1, \text { light green }=2, \text { green }=3 \text {, } \\
\text { green with purple spots }=4, \text { purple }=5, \\
\text { pink }=6\end{array}$ \\
\hline & No.57 hairgroup & $57 \mathrm{HG}$ & $\begin{array}{l}\text { The hair group in reverse side of leaf } \\
\text { sheath }\end{array}$ & None $=1$, sparse $=2$, thick $=3$ \\
\hline & Auricle & $\mathrm{Au}$ & A small earlike lobe or appendage & Degeneration $=1$, lanceolate $=2$, triangle $=3$ \\
\hline & Pulvinus & $\mathrm{Pu}$ & $\begin{array}{l}\text { outside of the junction of leaf blade } \\
\text { and sheath }\end{array}$ & None $=1$, have $=2$ \\
\hline
\end{tabular}

Table S3: Variations among 130 sugarcane parental lines for seven quantitative traits.

\begin{tabular}{ccccccc}
\hline Trait & Average & Min & Max & SD & CV (\%) & T-test for parental lines $^{\text {a }}$ \\
\hline PH & 301.55 & 200 & 385 & 40.52 & 13.44 & $84.85^{* *}$ \\
SD & 3.04 & 1.8 & 4.8 & 0.54 & 17.76 & $64.18^{* *}$ \\
IL & 12.11 & 6.5 & 20.0 & 2.42 & 19.97 & $57.09^{* *}$ \\
Bx & 23.03 & 14.8 & 26.7 & 2.31 & 10.02 & $113.79^{* *}$ \\
LL & 134.52 & 90 & 170 & 16.02 & 11.91 & $95.75^{* *}$ \\
LW & 5.02 & 2.4 & 8.5 & 0.95 & 19.01 & $59.98^{* *}$ \\
LAR & 27.63 & 15.3 & 44.4 & 5.43 & 19.65 & $58.02^{* *}$ \\
\hline
\end{tabular}

a “**” means significant at 0.01 levels.

Table S4: Statistics of seven quantitative traits in different subgroups.

\begin{tabular}{cccccccc}
\hline Subgroup & PH (cm) & SD (cm) & IL (cm) & Bx (\%) & LL (cm) & LW (cm) & LAR (\%) \\
\hline A & 291.3 & 4.0 & 10.3 & 20.4 & 120.0 & 6.0 & 20.4 \\
B & 340.0 & 3.7 & 15.0 & 20.9 & 130.0 & 5.3 & 24.5 \\
C & 263.3 & 2.8 & 8.6 & 24.4 & 137.5 & 3.2 & 5.1 \\
D & 290.0 & 3.2 & 11.5 & 22.8 & 126.0 & 25.9 \\
E & 299.1 & 3.0 & 12.2 & 23.4 & 135.3 & 4.9 & 27.9 \\
F & 306.8 & 3.0 & 12.4 & 23.0 & 136.0 & 5.0 & 27.9 \\
Mean & 301.5 & 3.0 & 12.1 & 23.0 & 134.5 & 5.0 \\
\hline
\end{tabular}

